DOI: $10.526 /$ cab.v14i3.18945

\title{
SUBSTITUIÇÃO DA FARINHA DE PEIXE POR FARINHA DE VÍSCERAS DE AVES NA ALIMENTAÇÃO DO PIAVUÇU Leporinus macrocephalus
}

 \\ ROGÉRIO BOSCOLO ${ }^{4}$, ALDI FEIDEN ${ }^{4}$
}

\author{
${ }^{1}$ Graduando em Engenharia de Pesca, Universidade Estadual do Oeste do Paraná, Toledo, PR, Brasil. \\ ${ }^{2}$ Pós-graduandos da Universidade Estadual Paulista Júlio de Mesquita Filho, Jaboticabal, SP, Brasil. \\ odairdiemer@hotmail.com \\ ${ }^{3}$ Pós-graduando da Universidade Estadual de Maringá, Maringá, PR, Brasil. \\ ${ }^{4}$ Professores Doutores da Universidade Estadual do Oeste do Paraná, Toledo, PR, Brasil.
}

\section{RESUMO}

O presente estudo teve como objetivo avaliar o desempenho produtivo de alevinos de piavuçu, alimentados com diferentes níveis de inclusão de farinha de vísceras de aves na substituição da farinha de peixe. $\mathrm{O}$ experimento foi conduzido em uma estufa localizada na Universidade Estadual do Oeste do Paraná durante um período de 45 dias. Foram utilizados 200 alevinos com comprimento inicial médio de $4,7 \pm 0,37 \mathrm{~cm}$ e peso inicial médio de 1,407 $\pm 0,03 \mathrm{~g}$, distribuídos em 20 tanques- redes. O delineamento experimental foi inteiramente casualizado com cinco tratamentos e quatro repetições com cinco níveis de substituição de farinha de peixe por farinha de vísceras de aves $(0,25,50,75,100 \%)$. Os parâmetros avaliados foram o desempenho produtivo e a composição química dos animais. A inclusão de farinha de vísceras de aves na substituição da farinha de peixe na alimentação de alevinos de piavuçu pode ser realizada sem comprometer o desempenho zootécnico dos animais.

PALAVRAS-CHAVE: aquicultura; nutrição; peixe nativo.

\section{REPLACEMENT OF FISH MEAL BY POULTRY VISCERA MEAL IN THE FEED OF Leporinus macrocephalus}

\section{ABSTRACT}

The present study aimed at evaluating the productive performance of Leporinus macrocephalus fed with different levels of inclusion of poultry viscera meal replacing fish meal. The experiment was conducted in a stove located in the Universidade Estadual do Oeste do Paraná during 45 days. We used 200 fish with average initial length of $4.7 \pm 0.37 \mathrm{~cm}$ and average initial weight of $1.407 \pm 0.03 \mathrm{~g}$, distributed in 20 net-cages. The experimental design was randomized with five treatments and five replicates with five levels of replacement of fish meal by poultry viscera meal $(0,25,50,75,100 \%)$. The parameters evaluated were the productive performance and the chemical composition of animals. The inclusion of poultry viscera meal in the substitution of fish meal in the feeding of Leporinus macrocephalus can be used without impairing the performance of the animals.

KEYWORDS: aquaculture; native fish; nutrition. 


\section{INTRODUÇÃO}

O piavuçu, Leoporinus macrocephalus, é encontrado nas bacias do rio Prata e Paraguai, sendo uma espécie com corpo alongado e fusiforme, com manchas escuras em seu corpo, podendo alcançar $60 \mathrm{~cm}$ de comprimento (ANDRADE et al., 2006). Apresenta hábito alimentar onívoro com tendência herbívora e consome uma ampla variedade de alimentos (RODRIGUES et al., 2006). Atualmente, é uma espécie muito utilizada na piscicultura por apresentar bons índices zootécnicos como: ganho de peso, conversão alimentar, crescimento, qualidade da carne e rusticidade (FEIDEN et al., 2009).

O Brasil apresenta um potencial imenso para aquicultura, pois possui clima favorável, ótimas condições de qualidade de água e principalmente uma grande diversidade de espécies de peixes. Além disso, apresenta um grande potencial hídrico (CAVALLI, 2011).

A criação de peixes de maneira geral requer a utilização da alimentação balanceada, à base de rações formuladas com diversos ingredientes e a partir de processos de fabricação diferentes (peletização e extrusão), para um melhor aproveitamento alimentar dos peixes. $\mathrm{O}$ emprego de rações responde hoje por mais de 50\% dos custos da piscicultura. Assim, ingredientes alternativos vêm sendo testados em diferentes dietas para peixes, visando principalmente a diminuição dos custos e fornecer mais opções de alimentos para a fabricação de rações que atendam às exigências nutricionais dos organismos cultivados (SIGNOR et al., 2007).

Uma das alternativas é o uso de farinha de vísceras de aves, um produto obtido de resíduos da indústria avícola resultante da prensagem $\mathrm{e}$ moagem das vísceras. Esse ingrediente apresenta bons níveis de proteína bruta, entre 55 a $68 \%$, e grande disponibilidade de cálcio e fósforo (PEZZATO et al., 2002). Com essas características, a farinha de vísceras de aves é uma ótima opção para substituição de fontes convencionais de proteína na formulação de rações para peixes.

Portanto, o objetivo do presente estudo foi avaliar o desempenho produtivo de alevinos de piavuçu (Leporinus macrocephalus) alimentados com diferentes níveis de inclusão de farinha de vísceras de aves na substituição da farinha de peixe.

\section{MATERIAL E MÉTODOS}

O experimento foi realizado entre os meses de abril e maio de 2009, com duração de 45 dias, foi conduzido em uma estufa localizada na Universidade Estadual do Oeste do Paraná (UNIOESTE), campus de Toledo-PR, e contou com o apoio do Grupo de Estudos e Manejo em Aquicultura (GEMAq).

Foram utilizados 200 alevinos de piavuçu com comprimento médio inicial de 4,7 $\pm 0,37 \mathrm{~cm}$ e peso inicial médio de $1,407 \pm 0,03 \mathrm{~g}$, distribuídos em 20 tanques-rede com volume útil de 150 litros, dispostos dentro de um tanque de alvenaria circular de $25 \mathrm{~m}^{3}$, que apresenta aeração constante por meio de mangueiras conectadas a um soprador de ar central.

O delineamento utilizado foi o inteiramente casualizado, com cinco tratamentos e quatro repetições, sendo a unidade experimental composta por um tanque-rede contendo 10 alevinos. Os tratamentos foram formados por cinco rações com cinco níveis de substituição de farinha de peixe por farinha de vísceras de aves $(0$, $25,50,75,100 \%)$, sendo isoenergéticas, isoprotéicas e isoaminoacídicas em lisina, metionina e treonina (Tabela 1). O arraçoamento foi realizado quatro vezes ao dia às $8 \mathrm{~h} 00 \mathrm{~min}$, $11 \mathrm{~h} 00 \mathrm{~min}, 14 \mathrm{~h} 00 \mathrm{~min}$ e $17 \mathrm{~h} 00 \mathrm{~min}$, até a saciedade aparente.

Para a preparação das rações, os ingredientes foram moídos em moinho tipo martelo com peneira de $0,5 \mathrm{~mm}$ de diâmetro de abertura, misturados manualmente conforme a formulação, posteriormente processadas por meio de extrusão com extrusora com capacidade de produção de 10 $\mathrm{kg} / \mathrm{h}$ e depois secas em estufa com ventilação forçada a $55^{\circ} \mathrm{C}$ por 24 horas.

Os parâmetros físico-químicos da água oxigênio dissolvido, $\mathrm{pH}$ e condutividade elétrica foram monitorados semanalmente por aparelhos eletrônicos. A temperatura da água foi monitorada duas vezes ao dia, antes da primeira e da última alimentação. Semanalmente, foram realizadas análises de água no tanque circular aferindo amônia, nitrito e fósforo como descrito por DIEMER et al. (2010). 
Tabela 1. Composição percentual das rações experimentais com diferentes níveis de inclusão de farinha de vísceras de aves na substituição da farinha de peixe

\begin{tabular}{|c|c|c|c|c|c|c|}
\hline \multirow{2}{*}{ Ingredientes $(\%)$} & \multicolumn{6}{|c|}{ Níveis de substituição (\%) } \\
\hline & $0,00 \%$ & $25,00 \%$ & $50,00 \%$ & & & $100,00 \%$ \\
\hline Farinha de vísceras & 29.89 & 22.42 & 14.95 & & & 0.00 \\
\hline Farelo de soja & 29.89 & 30.10 & 30.38 & & & 30.87 \\
\hline Milho grão & 27.44 & 28.30 & 29.12 & & & 30.83 \\
\hline Óleo de Soja & 6.00 & 5.98 & 5.29 & & & 3.92 \\
\hline Fosfato bicálcico & 2.16 & 1.62 & 1.08 & & & 0.00 \\
\hline Premix* & 1.00 & 1.00 & 1.00 & & & 1.00 \\
\hline Sal & 0.49 & 0.49 & 0.49 & & & 0.49 \\
\hline Lisina & 2.94 & 2.22 & 2.15 & & & 2.00 \\
\hline Metionina & 0.14 & 0.12 & 0.08 & & & 0.00 \\
\hline Treonina & 0.03 & 0.02 & 0.01 & & & 0.00 \\
\hline BHT & 0.02 & 0.02 & 0.02 & & & 0.02 \\
\hline Farinha de peixe & 0.00 & 7.72 & 15.44 & & & 30.87 \\
\hline Total & 100.00 & 100.00 & 100.00 & & & 100.00 \\
\hline \multicolumn{7}{|l|}{ Nutrientes } \\
\hline \multicolumn{2}{|l|}{ Amido (\%) } & 20 & 20 & 20 & 20 & 20 \\
\hline \multicolumn{2}{|l|}{ Cálcio (\%) } & 2.0 & 2.0 & 2.0 & 2.0 & 2.0 \\
\hline \multicolumn{2}{|c|}{ Energia digestível peixes $(\mathrm{kcal} / \mathrm{kg})$} & 3.500 & 3.500 & 3.500 & 3.500 & 3.500 \\
\hline \multicolumn{2}{|c|}{ Fósforo total $(\%)$} & 1.4 & 1.4 & 1.4 & 1.4 & 1.4 \\
\hline \multicolumn{2}{|l|}{ Proteína bruta (\%) } & 36 & 36 & 36 & 36 & 36 \\
\hline
\end{tabular}

No final do período experimental, os peixes foram mantidos em jejum por 24 horas e anestesiados com Eugenol® $\left(60 \mathrm{mg} . \mathrm{L}^{-1}\right)$, em seguida foram feitas as medidas individuais de peso $(\mathrm{g})$, comprimento total $(\mathrm{mm})$ e sobrevivência. Posteriormente, foram determinados o ganho de peso, conversão alimentar, taxa de crescimento especifico (TCE) e fator de condição (FC). O ganho de peso foi determinado por (peso final - peso inicial), a conversão alimentar por (ganho de peso / quantidade de ração fornecida), a taxa de crescimento especifico conforme a equação: $\mathrm{TCE}=$ [(ln peso médio final $(\mathrm{g})-\ln$ peso médio inicial (g))/tempo de experimento (dias)] x 100 e o fator de condição através da fórmula: $\mathrm{FC}=$ $\left[\mathrm{Peso} /\left(\right.\right.$ Comprimento total $\left.\left.^{-3}\right) \times 100\right]$. Em seguida, foram retirados, aleatoriamente, dois peixes de cada tanque-rede para análise da composição química do peixe inteiro, sendo avaliadas umidade (UM), proteína bruta $(\mathrm{PB})$, extrato etéreo (EE) e matéria mineral (MM), segundo metodologia descrita no (SIMÕES et al., 2007).

Os dados referentes aos parâmetros avaliados foram tabulados e submetidos à análise de variância e regressão através do programa estatístico SISVAR versão 5.3 (UFLA, 2010).

\section{RESULTADOS E DISCUSSÃO}

Os parâmetros físicos e químicos da água dos tanques-rede permaneceram dentro da faixa das condições ideais para criação de peixes (DIEMER et al., 2010): temperatura $22 \pm 1,21^{\circ} \mathrm{C}$ (manhã) e $23 \pm$ $1,25^{\circ} \mathrm{C}$ (tarde); oxigênio dissolvido $4,93 \pm 1,64$ mg. $\mathrm{L}^{-1} ; \mathrm{pH} 7,46 \pm 0,42$; condutividade elétrica $108,79 \pm 37,59 \mu \mathrm{S} . \mathrm{cm}^{-1}$; amônia $0,08 \mathrm{mg} . \mathrm{L}^{-1}$; fósforo $0,13 \mathrm{mg} \cdot \mathrm{L}^{-1}$ e nitrito $0,03 \mathrm{mg} \cdot \mathrm{l}^{-1}$.

Para todos os parâmetros de desempenho produtivo avaliados, não foram observadas diferenças estatísticas $(\mathrm{P}>0,05)$ pela analise de variância e regressão (Tabela 2 ).

O resultado deste experimento pode ser explicado devido às características similares que os dois ingredientes apresentam. PEZZATO et al. (2002) avaliaram a digestibilidade aparente de ingredientes pela tilápia do Nilo (Oreochromis niloticus) e entre os ingredientes estavam a farinha de peixe e a farinha de vísceras de aves. Com base nos resultados, os autores relataram que a farinha de vísceras de aves apresentou os melhores coeficientes de digestibilidade aparente seguida da farinha de peixes. 
Tabela 2 - Valores médios dos parâmetros de desempenho produtivo de alevinos de piavuçu ( $L$. macrocephalus) alimentados com diferentes níveis de inclusão de farinha de vísceras de aves na substituição da farinha de peixe

\begin{tabular}{lcccccc}
\hline \multirow{2}{*}{ Parâmetros } & \multicolumn{9}{c}{ Níveis de Substituição da FP por FV (\%) } & \multirow{2}{*}{ CV (\%) } \\
\cline { 2 - 6 } & 0 & 25 & 50 & 75 & 100 & \\
\hline Peso inicial (g) & 1,36 & 1,34 & 1,37 & 1,33 & 1,30 & $4,90^{\text {ns }}$ \\
Peso final (g) & 8,79 & 8,63 & 7,86 & 8,56 & 8,69 & $16,9^{\text {ns }}$ \\
Comprimento final (cm) & 8,64 & 8,40 & 8,15 & 8,45 & 8,28 & $4,44^{\text {ns }}$ \\
Ganho de peso (g) & 7,38 & 7,23 & 6,56 & 7,16 & 7,28 & $20,1^{\text {ns }}$ \\
Sobrevivência (\%) & 90,0 & 82,0 & 80,0 & 97,0 & 82,5 & $16,4^{\text {ns }}$ \\
Conversão alimentar aparente & 0,52 & 0,41 & 0,44 & 0,34 & 0,50 & $23,5^{\text {ns }}$ \\
Taxa de crescimento específico & 4,06 & 3,99 & 3,81 & 3,99 & 4,13 & $10,1^{\text {ns }}$ \\
Fator de condição & 1,35 & 1,43 & 1,46 & 1,40 & 1,52 & $5,93^{\text {ns }}$ \\
\hline
\end{tabular}

ns - não significativo $(\mathrm{P}>0,05)$.

A farinha de vísceras de aves é um alimento deficiente em metionina, lisina e triptofano (FARIA et al., 2002). Na composição das rações deste experimento, foram feitas suplementações desses aminoácidos para serem mantidos os mesmos níveis aminoacídicos, o que pode explicar a não ocorrência de diferenças no desempenho zootécnico.

Diversos trabalhos científicos demonstraram o sucesso da utilização da farinha de vísceras de aves na alimentação de peixes. Entre eles, destacam-se o de BOSCOLO et al. (2005a), que estudaram a farinha de vísceras de aves em rações para a Tilápia do Nilo (Oreochromis niloticus) durante a fase de reversão sexual e o de SIGNOR et al. (2008), que analisaram a farinha de vísceras de aves na alimentação de alevinos de lambari (Astyanax altiparanae).

FINKLER et al. (2010), ao analisarem a substituição da farinha de peixe por farinha de vísceras de aves na alimentação de alevinos híbridos de piavuçu, relataram que a substituição de até $50 \%$ pode ser feita sem causar alterações no desempenho; contudo, valores maiores que $50 \%$ prejudicam o ganho de peso, a conversão alimentar e a sobrevivência, discordando dos resultados deste experimento, que não demonstraram nem melhoras nem pioras no desempenho produtivo.

Os valores de umidade, proteína bruta, lipídios e cinzas do corpo do peixe inteiro no presente experimento não apresentaram diferenças $(\mathrm{P}>0,05)$ nos diferentes níveis de substituição (Tabela 3).

Tabela 3 - Composição química do peixe inteiro na matéria natural de alevinos de piavuçu ( $L$. macrocephalus) alimentados com diferentes níveis de inclusão de farinha de vísceras de aves na substituição da farinha de peixe

\begin{tabular}{lcccccc}
\hline \multirow{2}{*}{ Parâmetros } & \multicolumn{7}{c}{ Níveis de substituição } & \multirow{2}{*}{ CV (\%) } \\
\cline { 2 - 6 } & 0 & 25 & 50 & 75 & 100 & \\
\hline Umidade (\%) & 71,46 & 71,74 & 71,74 & 70,69 & 71,86 & $1,33^{\text {ns }}$ \\
Proteína bruta (\%) & 14,83 & 14,50 & 14,30 & 14,64 & 14,47 & $5,35^{\text {ns }}$ \\
Lipídios (\%) & 9,59 & 9,51 & 9,13 & 9,66 & 9,63 & $18,96^{\text {ns }}$ \\
Cinzas (\%) & 2,87 & 3,06 & 2,99 & 3,13 & 2,92 & $6,30^{\text {ns }}$ \\
\hline
\end{tabular}

ns - não significativo $(\mathrm{P}>0,05)$.

Os diferentes níveis de substituição de farinha de vísceras de aves não influenciaram na deposição de nutrientes. Resultados semelhantes foram descritos por FINKLER et al. (2010), que não observaram diferenças para a substituição da farinha de peixe por farinha de vísceras de aves na composição química da carcaça de híbridos de piavuçu, além de obterem composição química similar ao deste estudo.

BOSCOLO et al. (2005b), avaliando a inclusão de farinha de resíduos da indústria de filetagem de tilápia em rações para alevinos de piavuçu (Leporinus macrocephalus), observaram que a farinha de tilápia influenciou positivamente na 
deposição de proteína bruta, demonstrando que a inclusão de farinha de resíduos de filetagem de tilápia na dieta proporciona uma melhor qualidade nutricional do pescado, caso não verificado neste experimento.

A composição bromatológica dos peixes é constituída principalmente por meio da composição dos nutrientes fornecidas, ou seja, o consumo de uma ração desbalanceada pelos peixes pode implicar diferentes níveis de nutrientes corporais (SIGNOR et al., 2007). Neste experimento, não foram observadas diferenças na composição química da carcaça (Tabela 3), o que pode estar diretamente relacionado ao correto balanceamento dos nutrientes fornecidos aos animais.

\section{CONCLUSÃO}

A inclusão de farinha de vísceras de aves na substituição da farinha de peixe na alimentação de alevinos de piavuçu pode ser realizada sem comprometer o desempenho zootécnico dos peixes.

\section{REFERÊNCIAS}

ANDRADE, L. S.; HAYASHI. C.; SOARES, C. M. Refúgios artificiais coloridos e o desempenho e sobrevivência de alevinos de Leporinus macrocephalus (Garavello \& Britsky, 1988). Ciência Rural, v.36, n.1, jan-fev, 2006.

BOSCOLO, W.R.; MEURER, F.; FEIDEN, A.; HAYASHI, C. REIDEL, A.; GENTELINE, A. L. Farinha de vísceras de aves em rações para a tilápia do Nilo (Oreochromis niloticus) na fase de reversão sexual. Revista Brasileira de Zootecnia, v.34, n.2, p.373-377, 2005a.

BOSCOLO, W.R.; SIGNOR, A.; FEIDEN, A.; SIGNOR, A.A.; SCHAEFER, L.A.; REIDEL, A. Farinha de resíduo da filetagem de tilapia em rações para alevinos de Piavuçú, (Leporinus macrocephalus). Revista Brasileira de Zootecnia, v.34, n.6, p.1819-1827, 2005b.

CAVALLI, R. O. ; DOMINGUES1, E. C.; HAMILTON, S. Desenvolvimento da produção de peixes em mar aberto no Brasil: possibilidades e desafios. Revista Brasileira de Zootecnia. v.40, p.155-164, 2011.

DIEMER, O.; NEU, D.H.; FEIDEN, A.; LORENZ, E.V.; BITTENCOURT, F.; BOSCOLO, W.R. Dinâmica nictimeral e vertical das características limnológicas em ambiente de criação de peixes em tanques-rede. Ciência Animal Brasileira, v. 11, n. 1, p. 24-31, 2010.

FARIA, A.C.E.A.; HAYASHI, C.; SOARES, C.M. Farinha de vísceras de aves em rações para alevinos de tilápia do Nilo, Oreochromis niloticus. Revista Brasileira de Zootecnia, v.31, n.2, p.812- 822, 2002.

FEIDEN, A. SIGNOR, A. A.; BOSCOLO, W. R.; SIGNOR, A.; REIDEL, A. Exigência de proteína de alevinos de piavuçú. Ciência Rural. v.39, n.3, p. 859-865, 2009.

FINKLER J. K. FREITAS, J. M. A.; SIGNOR, A. A. ZAMINHAM, M.; BOSCOLO, W.; FEIDEN, A. Substituição da farinha de peixe por farinha de vísceras de aves na alimentação de alevinos híbridos de piavuçú, Boletim Instituto da Pesca, v.36, n.3, p.237 - 243, 2010.

PEZZATO, L.E.; MIRANDA, E.C.; BARROS, M.M. Digestibilidade aparente de ingredientes para a tilápia do Nilo (Oreochromis niloticus). Revista Brasileira de Zootecnia, v.31, n.4, p.1595-1604, 2002.

RODRIGUES, S. S.; NAVARRO, R. D.; MENIN, E. Adaptações anatômicas da cavidade bucofaringiana de Leporinus macrocephalus Garavello \& Britski, 1988 (Characiformes, Anostomidae) em relação ao hábito alimentar. Biotemas, v.19, n.1, p.51-58, 2006.

SIGNOR, A. A.; BOSCOLO, W. R.; BITTENCOURT, F.; FEIDEN, A.; REIDEL, A. Farinha de vísceras de aves na alimentação de alevinos de lambari. Ciência Rural, v.38, n.8, p.2339-2344, 2008.

SIGNOR, A. A.; BOSCOLO, W. R.; FEIDEN, A.; REIDEL, A.; SIGNOR, A.; GROSSO, I. R. Farinha de vísceras de aves na alimentação de alevinos de piavuçu (Leporinus macrocephalus). Ciência Rural, v.37, n.3, p.828-834, 2007.

SIMÕES, M. R.; RIBEIRO, C. F. A.; RIBEIRO, S. C. A.; PARK, K. J.; MURR, F. E. X. Composição físicoquímica, microbiológica e rendimento do filé de tilápia tailandesa (Oreochromis niloticus). Ciência e Tecnologia de Alimentos, v. 27, n. 3, p. 608-613, 2007. 